\title{
Influence de la nature des lipides ingérés sur la digestibilité des parois et les paramètres fermentaires du rumen
}

\author{
Y Elmeddah, M Doreau
}

INRA, laboratoire de la lactation, Theix, 63122 Saint-Genès-Champanelle, France

\begin{abstract}
Summary - Influence of the nature of the lipid supplement added to the diet on fibre digestibility and fermentation in the rumen. The influence of fat source on ruminal digestion and in sacco disappearance was studied in rations fed to cows. Fat supplementation $(6 \%$ of the diet) tended to decrease organic matter (OM) and cell wall digestibility and $\mathrm{C}_{2} / \mathrm{C}_{3}$ ratio but increased $\mathrm{pH}$. Our data support the hypothesis that $\mathrm{Ca}$ soaps had less negative effects on rumen fermentation than oil.
\end{abstract}

L'addition de matières grasses non protégées dans les rations de vaches laitières provoque souvent des effets néfastes sur la digestion des parois cellulaires (Palmquist, 1984). Pour éviter ces effets négatifs, plusieurs moyens ont été utilisés (Doreau et al, 1989). L'un d'eux consiste à les distribuer sous forme de savons de calcium, théoriquement insolubles dans le rumen, évitant ainsi les perturbations digestives à ce niveau. Aussi, l'objectif de ce présent travail est de comparer une source de savons de $\mathrm{Ca}$ d'acides gras d'huile de colza, à leur équivalent sous forme de triglycérides et d'évaluer leur incidence sur la digestibilité totale, la dégradabilité in sacco et sur les paramètres fermentaires du rumen de vaches laitières.

\footnotetext{
Matériel et méthodes - Trois vaches laitières (poids vif moyen: $615 \mathrm{~kg}$, production laitière moyenne : $26 \mathrm{~kg}$ ) porteuses de canules du rumen et du duodénum, en milieu de lactation, ont été utilisées selon un carré latin $3 \times 3$ avec 3 régimes : témoin ( $T$ ), savons de $\mathrm{Ca}(\mathrm{Ca})$ et huile $(\mathrm{H})$. Des rations à base d'ensilag $\Rightarrow$ de maïs étaient complémentées par un même concentré de production $120 \%$ blé, $20 \%$ orge, $30 \%$ pulpes de betterave, $15 \%$ tourteau de colza, $7 \%$ tourteau de soja, $5 \%$ mélasse, $1 \% \mathrm{CaCO}_{3}, 1 \%$ phosphate bicalcique, $0,5 \%$ magnésie, $0,5 \% \mathrm{NaCl}$ ), de tourteau de soja et d'un complément minéral et vitaminique. Le pourcentage de concentré dans la ration totale était voisin de $32 \%$. Le rationnement a été fait de manière que les quantités de matière sèche ingérée soient les mêmes pour les 3 traitements et que les 2 régimes supplémentés en lipides aient la
}

même composition que celle du témoin, leur fraction lipidique étant exclue. Les animaux de lots supplémentés en matière grasse ont reçu $1,27 \mathrm{~kg}$ de savons de calcium, sous forme de poudre, contenant $77 \%$ d'acides gras (AG) et $1,00 \mathrm{~kg}$ d'huile de colza par animal et par jour mélangés à la ration totale. Cette dernière était distribuée une fois par jour, le matin. La teneur totale en lipides totaux du régime témoin est de $3,2 \%$ contre $9,4 \%$ pour les régimes supplémentés en lipides. Les apports de calcium ont été équilibrés pour les 3 régimes et représentaient $1,0 \%$ de la ration totale. Chaque période expérimentale comportait une période d'adaptation de 2 semaines suivie par une période de mesure de durée équivalente. La digestibilité de la matière organique (MO) et celle des parois (NDF et ADF) a été mesurée par collecte totale des fèces pendant $6 \mathrm{j}$. La dégradabilité in sacco a été mesurée par la technique des sachets de nylon contenant un foin (\% MO 92,9, \% NDF 68,8). Le $\mathrm{pH}$, les teneurs en ammoniac et en acides gras volatils (AGV) ainsi que leur composition ont été mesurés sur des échantillons de liquide de rumen prélevés juste avant le repas du matin, $1 \mathrm{~h}, 3 \mathrm{~h}$ et $7 \mathrm{~h}$ après ce même repas.

Résultats et discussion - Les quantités de MO, NDF et ADF ingérées sont significativement moins élevées avec le régime $\mathrm{Ca}$ que pour les 2 autres régimes $(P<0,05)$. La digestibilité de la MO est plus élevée dans le lot témoin que dans les lots supplémentés en lipides, mais la différence n'est significative qu'avec le régime $H$ (tableau I). Comparés au régime témoin, les traitements $\mathrm{H}$ et $\mathrm{Ca}$ enregistrent une chute de digestibilité respectivement de 3,4 et 
1,2 points. Les digestibilités des NDF et ADF ne sont pas significativement différentes entre traitements, mais la même tendance que sur la MO apparaît.

Avec le régime $\mathrm{H}$, la digestibilité du NDF et de l'ADF chute en moyenne de 6,5 points par rapport au témoin. Le régime $\mathrm{Ca}$ donne des résultats intermédiaires entre les traitements témoins et $H$. Ces valeurs vont dans le sens de celles obtenues par Jenkins et Palmquist (1984). Les cinétiques de dégradabilité in sacco (fig 1) confirment l'effet négatif de l'huile mais font apparaître que la dégradabilité des parois cellulaires avec le régime $\mathrm{Ca}$ est plus élevée, fait déjà observé par Palmquist et al (1986). Cet effet positif des savons de $\mathrm{Ca}$ sur la dégradabilité in sacco peut être 'ié au pH plus élevé observé avec ce traitement (tableau I) sans l'effet négatif sur la croissance bactérienne associé à l'incorporation de l'huile de colza riche en AG insaturés. Suite aux différences de proportions de $\mathrm{C} 2$ et $\mathrm{C} 3$ observées dans les régimes supplémentés en lipides comparés au témoin (tableau I), le rapport $\mathrm{C} 2 / \mathrm{C} 3$ diminue de $6 \%$ avec le traitement $\mathrm{Ca}$ et de $18 \%$ avec le traitement $H$. La concentration d'AGV tend à augmenter et celle de l'ammoniac à diminuer avec ces derniers régimes.

En conclusion, ces résultats confirment que la digestion ruminale est légèrement plus favorable avec les savons de calcium qu'avec l'huile, du
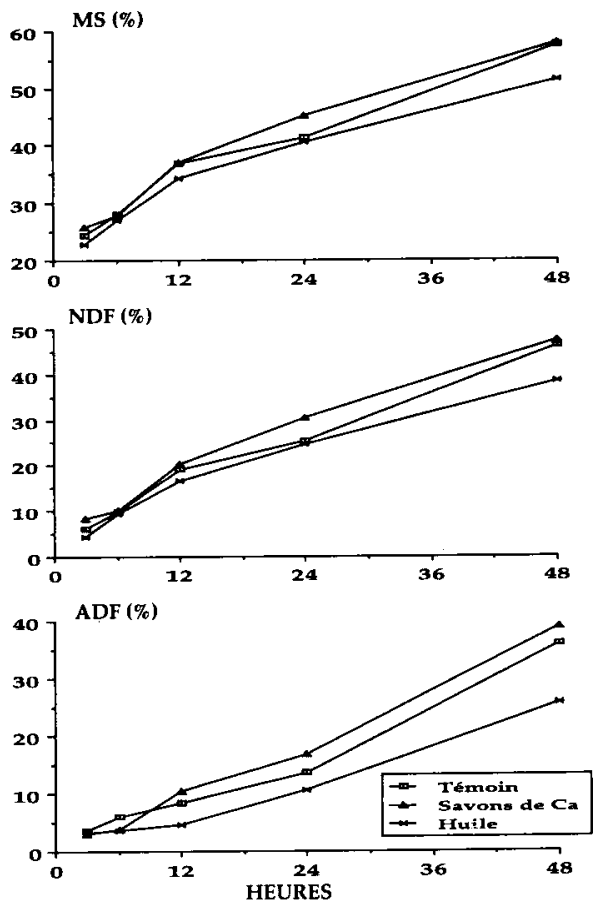

Fig 1. Cinétique de dégradation in sacco de la MS et des constituants pariétaux (\%).

moins au niveau du taux de supplémentation adopté dans cet essai.

Doreau M, Ferlay A, Elmeddah Y, Bauchart D (1989) Rev Fr Corps Gras 36, 271-278 Jenkins TC, Palmquist DL (1984) J Dairy Sci 67, 978-986

Palmquist DL (1984) In : Fats in animal nutrition (Wiseman, ed) Butterworths, London, 183-199

Palmquist $\mathrm{DL}$, Jenkins $T C$, Joyner $A E \mathrm{Jr}$ (1986) J Dairy Sci 69, 1020-1025

Tableau I. Influence de la nature des lipides ingérés sur la digestibilité totale, le $\mathrm{pH}$ et les produits terminaux de la digestion ruminale (valeurs moyennes des 4 prélèvements).

\begin{tabular}{|c|c|c|c|c|}
\hline Digestibilité & Témoin & Savons $\mathrm{Ca}$ & Huile & ETR \\
\hline 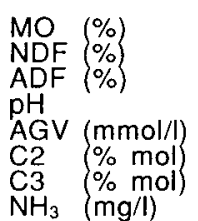 & $\begin{array}{c}72,1^{a} \\
65,0 \\
56,2 \\
6,19 \\
88 \\
65,7^{a} \\
17,3 \\
157\end{array}$ & $\begin{array}{c}71,3^{\mathrm{ab}} \\
62,3^{3} \\
52,8 \\
6,36 \\
104 \\
65,8^{\mathrm{a}} \\
18,5 \\
131\end{array}$ & $\begin{array}{c}68,8^{\mathrm{b}} \\
58,5 \\
49,7 \\
6,34 \\
98 \\
62,8^{\mathrm{b}} \\
20,1 \\
126\end{array}$ & $\begin{array}{r}0,91 \\
2,03 \\
2,19 \\
0,07 \\
13,8 \\
0,81 \\
1,80 \\
20,6\end{array}$ \\
\hline
\end{tabular}

Sur une même ligne, les valeurs affectèes de lettres différentes diffèrent significativement $(P<0,05)$. 